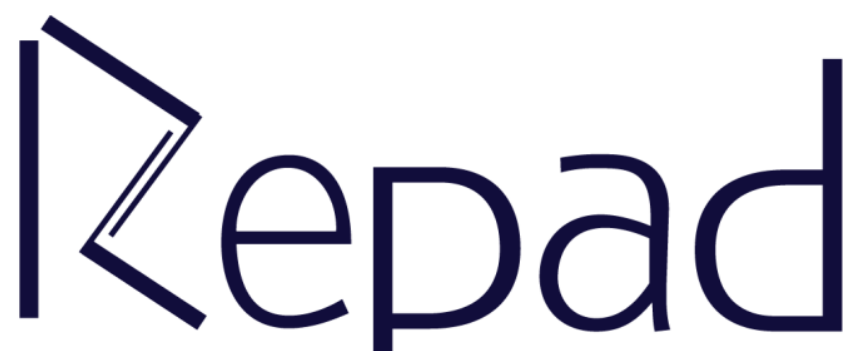

Vol. 3, n. 1, Abril/2019

Revista Estudos e

Pesquisas em Administração

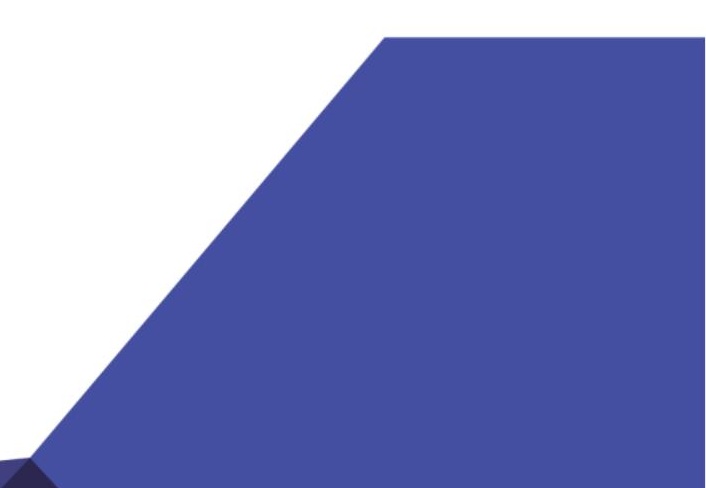




\title{
ELABORAÇÃO DO PLANEJAMENTO ESTRATÉGICO NO INSTITUTO FEDERAL DE MATO GROSSO/CAMPUS AVANÇADO TANGARÁ DA SERRA
}

\author{
Joseano Lira Santos \\ Universidade Federal de Sergipe \\ https://orcid.org/0000-0001-9809-9392 \\ Alessandra Nunes Gomes \\ INSTITUTO FEDERAL DE MATO GROSSO/CAMPUS AVANÇADO TANGARÁ DA \\ SERRA \\ https://orcid.org/0000-0002-4905-8153 \\ André Luis Scudeler \\ INSTITUTO FEDERAL DE MATO GROSSO/CAMPUS AVANÇADO TANGARÁ DA \\ SERRA \\ https://orcid.org/0000-0002-1286-053X \\ Felipe Guedes Moreira Vieira \\ INSTITUTO FEDERAL DE MATO GROSSO/CAMPUS AVANÇADO TANGARÁ DA \\ SERRA \\ https://orcid.org/0000-0002-3193-7045 \\ Nícolas da Silva de Lima \\ INSTITUTO FEDERAL DE MATO GROSSO/CAMPUS AVANÇADO TANGARÁ DA \\ SERRA \\ https://orcid.org/0000-0003-3918-9974 \\ Thaynára Orrana Pereira Pareci \\ INSTITUTO FEDERAL DE MATO GROSSO/CAMPUS AVANÇADO TANGARÁ DA \\ SERRA \\ https://orcid.org/0000-0003-4554-5904
}

\section{RESUMO}

A denominação de Planejamento Estratégico constitui um conjunto de ações refletidas ao longo de um período de tempo para que se alcancem objetivos e metas. As ações utilizadas para que os objetivos sejam alcançados são definidas através da estratégia, enquanto o planejamento está relacionado à organização de cada uma destas decisões. Propõe-se uma abordagem delimitada relacionada ao Planejamento Estratégico, escrito num formato comparado ao Plano de Desenvolvimento Institucional cuja ferramenta é utilizada em Instituições Públicas, como órgãos escolares, para que eles se desenvolvam de maneira adequada; sendo o primeiro fruto do mercado empresarial, um instrumento de tomada de decisões adotado por quase todas as companhias do mercado, e com seu foco voltado para o aumento da produtividade e consequentes lucros. A referida pesquisa, empírica, é de base exploratória e descritiva, de análise bibliográfica e documental, com resultado qualitativo, no qual elaborou-se a pesquisa identificando as fases, as características e as vantagens do documento estratégico. Um dos pontos principais que relaciona os planejamentos em tela, é o estabelecimento da tríade missão, visão e valores da instituição onde serão implantados. Além disso, outro ponto em comum são suas vantagens, as quais visam a consolidação do trabalho, eficiência e eficácia das tarefas empregadas.

Palavras-chave: Planejamento Estratégico, Plano de Desenvolvimento Institucional, Instituto Federal. 


\title{
ELABORATION OF STRATEGIC PLANNING AT THE FEDERAL INSTITUTE OF MATO GROSSO / CAMPUS ADVANCED TANGARÁ DA SERRA
}

\begin{abstract}
The name of Strategic Planning is a set of actions reflected over a period of time in order to achieve goals and targets. The actions used to achieve the objectives are defined through strategy, while planning is related to the organization of each of these decisions. It proposes a delimited approach related to Strategic Planning, written in a format compared to the Institutional Development Plan. This being a tool used in Public Institutions, such as school organs, so that they develop properly, being the first fruit of the business market, a decisionmaking instrument adopted by almost all companies in the market, with its focus on increasing productivity and consequent profits. This study is based on an exploratory and described bibliographic and documentary analysis, with a qualitative result, in which the research was elaborated identifying the phases, characteristics and advantages of the strategic document. One of the main points that relates the screen plans is the establishment of the triad's mission, vision and values of the institution where they will be implemented. In addition, another point in common is its advantages, which aim at consolidating the work, efficiency and effectiveness of the tasks employed.
\end{abstract}

Keywords: Strategic Planning, Institutional Development Plan, Federal Institute

Datas Editoriais

\section{INTRODUÇÃO}

Submetido: $18 / 12 / 2018$

Aceito: $24 / 03 / 2019$

Publicado: 28/04/2019

Decorrente da globalização, onde diariamente ocorrem fluxos e trocas de informações e conhecimento devido à facilidade de comunicação, as empresas tendem a desenvolver ferramentas que hajam com efetividade em relação à competitividade entre as organizações. Uma vez aplicadas, a organização já detém de uma vantagem sobre às que não a implementam.

Para que as empresas tenham a possibilidade de crescer no mercado é importante que se tenha um planejamento bem definido e desenvolvido, pois um bom plano impulsiona as ações e metas estabelecidas pelo empreendimento à direção correta, auxiliando para que ela possa antecipar-se, e evitar futuros problemas decorrentes de um planejamento mal desenvolvido e aplicado.

Nesse sentido, o Planejamento Estratégico (PE) visa a formulação de estratégias que preparam a organização para um futuro incerto, com base no meio onde está inserida, sendo possível fazer uma análise de suas vantagens e aplicá-las dentro da instituição com o objetivo de se prevenir de futuras complicações e tornar-se altamente competitiva.

Logo, para que a organização se desenvolva de forma eficiente e eficaz, é necessário a implantação de seu PE que, Kotler (2015) um dos defensores da sua utilização, define-o como uma metodologia gerencial que permite estabelecer a direção a ser seguida pela organização.

Portanto, o PE visa maior grau de interação com o ambiente, sendo que essa ferramenta estratégica não está disponível apenas às empresas comerciais, mas também às instituições públicas, filantrópicas, como exemplo das instituições educacionais, pois ao implantarem em suas gestões administrativas, desenvolvem-se com mais robustez.

Conforme mencionado, o planejamento estratégico não se aplica somente em organizações comerciais, mas também em outras instituições, mesmo que revestido de outras nomenclaturas, como acontece nos Institutos Federais de Ensino, cujo planejamento estratégico 
é denominado de Plano de Desenvolvimento Institucional (PDI), sendo esse padronizado para todas as instituições presentes no território nacional, em atendimento à Lei Federal $\mathrm{n}^{\circ} 10.861$, de 14 de abril de 2004.

O PDI tem como objetivo a melhoria da Instituição na qual está sendo implantada, tendo como referências sua infraestrutura, funcionários e gerenciamento. $\mathrm{O}$ mesmo visa, assim como o planejamento estratégico, o aprimoramento no desempenho efetivo da referente organização, estabelecendo a direção a ser seguida pela instituição.

No desenvolvimento deste trabalho, serão apresentados tópicos sobre o planejamento estratégico, bem como as suas fases de implantação, suas principais características e as vantagens da organização, ao final da implantação de um planejamento estratégico, fazendo uma perspectiva comparada com o PDI do Campus Avançando Tangará da Serra/MT, de modo que se possa apresentar a grande semelhança existente entre o Plano de Desenvolvimento Institucional e o Planejamento Estratégico.

\section{CONCEPÇÃO DO PLANEJAMENTO ESTRATÉGICO}

Hindle (2002) afirma que os primeiros pensamentos envolvendo planejamento estratégico, originam-se da pré-história, onde houve a necessidade de começar a pensar em maneiras de estocar mantimentos. $\mathrm{O}$ autor utiliza como exemplos, os egípcios, babilônios e chineses em seu trabalho referente ao planejamento.

Logo, planejar consiste em elaborar, de maneira ordenada, metas e ações distintas que após analisadas e selecionadas, a escolha se resultará na melhor opção. Tal termo refere-se também, às consequências futuras que podem surgir dentro do ambiente organizacional ao se tomar decisões no presente. (BARBOSA; BRONDANI, 2005).

Partindo para a análise da palavra estratégia, essa originou-se em âmbito militar, na qual referia-se ao modo de batalha a ser executado para atingir devidos fins em uma guerra. Porém, trazendo a palavra para o contexto organizacional, obtém-se um melhor significado à palavra ao falar que corresponde ao trabalho contínuo de forma eficiente, atendendo sempre às exigências da organização, colocando os objetivos futuros da empresa como foco principal. (BARBOSA; BRONDANI, 2005)

Chiavenato (2006) fala que existem três modalidades de planejamento administrativo dentro dos níveis hierárquicos, sendo o estratégico, tático e operacional, os quais interligam-se nessa ordem.

Um dos principais objetivos ao falarmos de planejamento estratégico, consiste em determinar a missão, visão e valores, os quais a empresa deseja alcançar. E sobre essa tríade, Alday (2000) conceitua à missão organizacional como sendo a "finalidade de uma organização ou a razão de sua existência; a visão são desejos em que a empresa pretende-se tornar, e os valores expressam a filosofia que a norteia e que a diferencia". Tendo os três tópicos definidos, é possível saber onde se quer chegar, e definir o meio estratégico mais eficiente a se buscar. (ALMEIDA; MENEZES, 2013; ALDAY, 2000).

E como o PE apresenta grande importância para a empresa, tanto na construção de ações que impactarão no futuro quanto nas ações do presente, é de responsabilidade dos níveis mais altos da organização dar início à sua elaboração, uma vez que é preciso levar em consideração todas as condições existenciais da organização, tanto internas quanto externas na elaboração do mesmo, respeitando sempre limites e objetivos no qual se busca alcançar. (ALMEIDA; MENEZES, 2013). 


\section{AS FASES DE IMPLANTAÇÃO DO PLANEJAMENTO ESTRATÉGICO}

$\mathrm{Na}$ atualidade, o planejamento estratégico vem sendo uma ferramenta de grande uso para as organizações comerciais, e até mesmo para instituições públicas municipais, estaduais e federais, como é o caso do Instituto Federal de Mato Grosso, e especificamente do Campus avançado Tangará da Serra.

$\mathrm{Na}$ referida Instituição de Ensino, o planejamento estratégico é denominado Plano de Desenvolvimento Institucional (PDI), como também nos institutos de modo geral, independentemente se são públicas ou privadas, pois o referido plano tem a finalidade de elaborar ações, metas e estratégias a fim de alcançar resultados efetivos (Síntese do Plano de Desenvolvimento Institucional, IFMT, 2015).

O processo das etapas do PE, o qual é dividido, conforme Oliveira (2007) nas fases de diagnóstico estratégico, missão da empresa e os instrumentos prescritivos e quantitativos. Dando início ao diagnóstico, que consiste na análise detalhada dos aspectos da organização para saber "como está" em relação à realidade da empresa no âmbito interno e externo. Essa etapa é executada por pessoas qualificadas e específicas.

Ainda de acordo com Oliveira (2007) a fase diagnóstica do PE subdivide-se em análise interna e externa que, respectivamente, verificam-se os pontos fracos, fortes e neutros da organização e examina ameaças e oportunidades, proporcionando uma melhor forma de utilizar os seus resultados para resolver problemas em seu âmbito, com os maiores concorrentes.

Entende-se por pontos fortes, as variáveis internas e controláveis que proporcionam uma condição favorável à empresa, enquanto que os pontos fracos causam um desaproveito, ou seja, um problema conforme seu ambiente.

Sobre as oportunidades destacadas por Oliveira (2007), as mesmas são entendidas como uma força incontrolável pela empresa, as quais podem ser utilizadas em benefício da organização, conforme sua estratégia, já as ameaças também são incontroláveis e podem causar obstáculos nas ações do plano e de seus objetivos

Com o objetivo de minimizar efeitos adversos ou incontroláveis à organização, durante a fase de implantação do planejamento estratégico, uma ferramenta bastante utilizada pelas organizações para examinar o máximo esses fatores, é denominada de matriz SWOT (Strengths, Weaknesses, Opportunities e Threats), conhecida também como FOFA - Forças, Oportunidades, Fraquezas e Ameaças (KOTLER, 2015).

A matriz SWOT apresenta elementos constitutivos que sinalizam as contribuições da empresa (forças e oportunidades) como também os elementos que prejudicam ou interferem no seu desenvolvimento (fraquezas e ameaças). Essa ferramenta faz a análise de ambiente, tornando-se então de grande utilidade para o planejamento estratégico.

Oliveira (2007) aponta as fases de missão da empresa, sendo a segunda etapa pela qual determina-se o motivo da organização, mostra o seu posicionamento sobre a competitividade e também sua visão estratégica para alcançar seus objetivos. Sequencialmente, os instrumentos prescritivos e quantitativos, como terceiro passo, são fundamentais para análise dos objetivos organizacionais.

O referido autor menciona os elementos que devem constar para alcançar os objetivos pretendidos, de acordo com a missão da empresa e sua postura estratégica. Estabelecimento de objetivos; Desafios e metas; Estabelecimento de estratégias e políticas funcionais (estas são a base que sustenta o planejamento); Estabelecimento de planos de ação, e os quantitativos estão diretamente relacionados ao planejamento orçamentário e são devidamente ligados a estrutura organizacional da empresa (OLIVEIRA, 2007). 
Nota-se que esses instrumentos são necessários na elaboração de planos de ação e projetos previstos, sendo então de extrema importância.

A fase de controle e avaliação, quarta e última fase, é a que leva mais tempo, pois essa é a inspeção de como ocorre o processo planejado, se está de acordo ao objetivo (Oliveira, 2007). O autor menciona que nessa etapa, em sentido vasto, abrange técnicas de avaliação de desempenho, comparação do desempenho real com os objetivos pretendidos, desafios, metas e projetos estabelecidos e tomada de ação corretiva.

E por finalizar as fases de implantação do planejamento estratégico, a avaliação está presente em todas as fases do referido processo.

\section{AS PRINCIPAIS CARACTERÍSTICAS DO PLANEJAMENTO ESTRATÉGICO}

Matos (1999) afirma que o planejamento estratégico apresenta, como uma de suas principais características, a relação da organização com adaptação a lugares mutáveis.

Analogicamente acontece com o Plano de Desenvolvimento Institucional (PDI) o qual é baseado em decisões, no entanto, não tem como fonte, informações concretas referentes ao seu resultado que de fato é encarado como desafio para aprimorar a qualidade do processo de ensino.

Ainda, de acordo com Matos (1999), o planejamento estratégico é compreensível, pois envolve a organização como um todo e utiliza-se dos seus recursos, principalmente as pessoas.

Em sua síntese, o PDI do IFMT/2014/2018, menciona que "todas as ações realizadas no âmbito deste Instituto devem ser pautadas por um objetivo comum, a saber, a geração de conhecimentos socialmente referenciados".

Nesse sentido, a construção do PDI envolve todos os departamentos a fim de que seus membros compreendam a importância de participarem desse processo, pois a execução do plano bem como o atingimento das metas, dependem dos objetivos estratégicos traçados e compreensíveis por todos.

Outra característica fundamental presente no plano estratégico, é a instituição da missão, que, segundo Oliveira (2007), tem como objetivo deixar claro o motivo de sua existência e o público alvo de quem a organização quer atender.

Logo, a fase da missão institucional do PDI proposto pelo IFMT/2014/2018 é "Educar para a vida e para o trabalho", a qual deixa explícita o motivo de sua existência que consiste em preparar os alunos para o trabalho, mantendo a postura educacional.

Conforme Oliveira (2007), o Planejamento Organizacional está dividido em três partes, como o estratégico que consiste em ser responsável pela elaboração de objetivos que inclui a visão, missão e valores, em seguida o planejamento tático é responsável por resolver determinado resultado que não estava de acordo com o que foi planejado, tem-se como exemplo o impacto ambiental que pode influenciar no desenvolvimento de tarefas, e por fim, o planejamento operacional, pela qual consiste na execução das tarefas que foram planejadas.

Observa-se com a citação anterior de Oliveira, que a aplicação do Planejamento Organizacional, está inserido nos planos da instituição como a formação da visão, missão e valor.

De acordo com a Proposta de Relatório Diagnóstico do campus avançado Tangará da Serra,

A visão do IFMT nos próximos cinco anos é ser reconhecida como instituição pública referência de ensino e de qualidade, que aglutinem os eixos de ensino profissionalizante, pesquisa e extensão para o desenvolvimento regional e atendimento às necessidades locais (PDI/IFMT, 2018, p. 1) 
Pode-se observar que a proposta do relatório mostra que as decisões que foram tomadas, tiveram como linha de raciocínio o atendimento às necessidades locais, com o objetivo de recrutar pessoas para o ambiente educacional.

\section{AS PRINCIPAIS VANTAGENS DO PLANEJAMENTO ESTRATÉGICO}

Ackoff (1974) afirma que "o maior benefício do planejamento estratégico é o processo desenvolvido e não o resultado final, ou seja, o plano em si". O autor enfatiza ainda que o planejamento deve ser elaborado pela própria empresa e suas áreas pertinentes ao processo.

Logo, é notório que com a implantação do PE, haja benefícios por conta da aplicação dessa ferramenta.

O PE implica em medidas positivas voltadas para a organização, que, decorrente dele, poderá usufruir de benefícios encontrados em seu ambiente. Tais ambientes mudam com surpreendente rapidez, isso se dá por conta do crescimento recente do PE, crescimento pelo qual ocorre apenas se a empresa conseguir harmonizar-se à conjuntura, e o planejamento estratégico é uma técnica comprovada para que os ajustes sejam feitos de forma eficaz (ALDAY, 2000).

Desta forma, implantar o PE tornou-se um meio importante pois vai ao encontro de condições favoráveis no âmbito organizacional, buscando desenvolver a empresa de modo ativo e eficiente.

Com a implantação de um planejamento estratégico tornam-se visíveis algumas vantagens, sendo elas: maior alinhamento da empresa, melhor conhecimento sobre os clientes e concorrentes, maior comprometimento dos colaboradores a atingir os objetivos traçados e maior eficiência na tomada de decisões. Partindo disso, ficam claros os motivos pelas quais as empresas passaram a aderir essa estratégia (ALMEIDA; MENEZES, 2013).

Segundo o diretor do IFMT Campus avançado Tangará da Serra, o Plano de Desenvolvimento Institucional (PDI) está incluso como aquele que tem suas devidas vantagens. Esse planejamento tem como objetivo prever algumas situações e evitar alguns erros. Ele proporciona visão de futuro, fazendo com que algumas perguntas importantes sejam respondidas para o bom desempenho do Instituto, tais como: qual o valor em dinheiro terá disponível? Quais obras poderão ser feitas? Quantos servidores terão? Quais cursos poderão ou não ser oferecidos?

Então, o benefício de desenvolver-se um PDI está em consonância estratégica, a fim de evitar erros e surpresas desagradáveis. É o que corrobora Alday (2000), ao afirmar que a ausência da implementação efetiva da estratégia, proporciona incapacitação para que o organismo possa obter benefícios na realização de uma análise, do estabelecimento de uma diretriz, e da formulação da estratégia organizacional.

Sendo assim, o PE atua como aquele possibilita o enfrentamento de ameaças e o aproveitamento de oportunidades, voltando-se para as medidas positivas que uma empresa poderá tomar a partir da avaliação que é feita com o auxílio dessa ferramenta.

\section{RESULTADOS E DISCUSSÃO}

O Planejamento das Instituições Federais é provido de características que os identificam, como sua periodicidade de quatro anos e também a padronização entre os campi, já na elaboração do Plano de Desenvolvimento Institucional 2019/2023, houveram processos de desenvolvimento relacionado à ferramenta que, subdivide-se em quatro fases com 
delimitações de tempo definidas, sendo elas, diagnóstico, elaboração, consulta pública e acompanhamento.

O diagnóstico realizado entre junho e setembro baseou-se em capacitação dos servidores, formação de comissões, criação de e-mail constitucional relacionado ao PDI, seminários e oficinas explicativas sobre a elaboração do Plano.

Já na segunda fase, a elaboração, ocorrida em outubro, consistiu na atualização da Missão, Visão e Valores do antigo plano, definição da Matriz SWOT, mapa estratégico com objetivos e indicadores, coleta de dados e compilação dos documentos e consulta pública, onde tem como objetivo a interação com o público para a participação destes no desenvolvimento do PDI.

O acompanhamento terá início em janeiro de 2019, este baseia-se na sistematização do Planejamento Estratégico, fazendo uso do ForPDI, uma plataforma aberta para a gestão e acompanhamento de Plano de Desenvolvimento Institucional de universidades federais e outras instituições públicas. Posteriormente determina-se reuniões anuais de acompanhamento da execução do plano e ajustes necessários.

A implantação de um Plano de Desenvolvimento dentro de uma Instituição é um processo muito importante, uma vez que essa determinará todas as mudanças prescritas na construção do PDI, como obras em infraestruturas, aumento de vagas de pessoal, disponibilização de novos cursos, melhoria na gestão organizacional, dentre outros.

Tal processo é decorrente também da alta administração dos campi, ou seja, é elaborado de forma geral pela reitoria com um conselho de diretores de todas as unidades do IFMT, e aprofundado conforme as necessidades de cada campus.

Partindo disso, temos como exemplo dessa elaboração em conjunta, a atualização da missão, que no plano anterior consistia-se em "educar para a vida e para o trabalho" frase que foi atualizada da seguinte forma "educar para a vida e para o mundo do trabalho" no qual explicita a preparação de alunos para o mundo trabalho.

O mesmo está ocorrendo no Campus avançado Tangará da Serra, através de reuniões com os docentes, discentes, técnico-administrativos e também ao público que se interesse pelo assunto. Decorrente disso, houve a elaboração da proposta de relatório de diagnóstico, onde apresenta todo o plano que se busca alcançar dentro de quatro anos.

\section{CONSIDERAÇÕES FINAIS}

De acordo com os tópicos desenvolvidos, os quais foram feitos a partir de perspectiva comparada entre o Planejamento Estratégico (PE) - contido nas literaturas administrativas expostas - e o Plano de Desenvolvimento Institucional (PDI) - em elaboração pelo Instituto Federal de Mato Grosso/Campus Avançado Tangará da Serra, constatou-se que ambos seguem os mesmos princípios administrativos, porém, sendo o PE genérico e voltado para todas organizações, e o PDI específico e direcionado para as Instituições públicas de educação.

As vantagens da implantação de ambos os tipos de planejamento são inúmeras, com destaque para o envolvimento de todos funcionários, pertencentes aos níveis hierárquicos (estratégico, tático e operacional) da organização.

Foi tratado a importância do PE nos ambientes organizacionais, sabendo das vantagens das empresas ao implantar e executá-lo, pois possibilita o melhor funcionamento desta, e em instituições públicas, as quais necessitam de atenção e monitoramento constante, pois pertencem à toda sociedade. 
Diferente do planejamento estratégico em organizações privadas, percebe-se que o PDI das instituições públicas conta com a participação da sociedade, sendo essa, livre para debater o assunto e sugerir novas propostas, as quais atendam aos interesses coletivos, e todo corpo institucional.

Sabendo da existência do PDI, é possível que haja a cobrança por parte da população para o cumprimento das propostas elaboradas no plano, criando assim uma vigilância por parte dos próprios usuários inseridos nesses meios públicos.

Sugere-se ao término da vigência do referido PDI 2019/2023, uma nova pesquisa, a fim de comparar a avaliação das metas traçadas, aos objetivos alcançados.

\section{REFERÊNCIAS}

ACKOFF, R. L. Planejamento empresarial. Rio de Janeiro: LTC, 1974.

ALDAY, H. E. C. O Planejamento Estratégico dentro do Conceito de Administração Estratégica. Curitiba: revista da FAE, maio e agosto de 2000, v 3, nº 2, p. 9-16.

ALMEIDA, A. A.; MENEZES, J. F. A importância do planejamento estratégico como fator preponderante ao crescimento organizacional. Lagarto: revista eletrônica, setembro de 2013, no 8 , p. 60-76.

BARBOSA, E. R.; BRONDANI, G. Planejamento estratégico organizacional. Santa Maria: revista eletrônica de contabilidade, fevereiro de 2005, v 1, nº 2, p.107-123.

CHIAVENATO, I. Administração estratégica. São Paulo: Saraiva, 2006.

HINDLE, T. Tudo sobre administração. São Paulo: Editora Nobel, 2002.

KOTLER, P. Marketing para o século XXI: como criar, conquistar e dominar mercados. São Paulo: Futura, 2015.

MATOS, F. G., CHIAVENATO, I. Visão e ação estratégica. São Paulo: Editora Makron Books, 1999.

OLIVEIRA, D. P. R. Planejamento Estratégico: conceitos, metodologia e práticas $-23^{\mathrm{a}}$ ed. São Paulo: Atlas, 2007. 